\title{
ELEMENTOS PARA UMA ANÁLISE DOS ESTUDANTES COTIS- TAS E BOLSISTAS NO CURSO DE PEDAGOGIA DA UFRJ
}

\author{
Rosana Heringer \\ Gabriela de Souza Honorato **
}

\begin{abstract}
O artigo trata da grande expansão nas oportunidades de acesso à educação superior no Brasil, com ênfase especial ao caso de uma de suas maiores instituições - a Universidade Federal do Rio de Janeiro. Apontamos e refletimos sobre as primeiras dificuldades metodológicas encontradas na construção de instrumentos de levantamento de dados como o survey e as entrevistas semiestruturadas, utilizados ao tomarmos como objeto de estudo os alunos do curso de Pedagogia com ingresso em 2011 e 2012 (primeiras turmas com reserva de vagas para estudantes de escolas públicas), e com um perfil, já histórico, de dificuldades econômicas e culturais para a conclusão dos estudos. As reflexões reunidas sintetizam alguns dos limites e desafios potencialmente colocados nos estudos que pretendem contribuir para o planejamento, o desenho e a implementação de políticas institucionais de democratização do acesso, da permanência e de assistência aos ditos "novos estudantes".
\end{abstract}

Palavras-chave: Metodologia. Educação superior. Ação afirmativa.

A última década foi marcada pela ampliação das oportunidades de acesso à educação superior no Brasil. O número de matrículas, de 2003 a 2013, aumentou 85,6\%, passando de 3,9 para 7,3 milhões. ${ }^{1}$ Quando se trata de ingressantes, o país tem superado, na maioria das áreas de conhecimento, os números da Organização para a Cooperação e o Desenvolvimento Econômico (OCDE). Na área de educação, o número de ingressantes para cada dez mil brasileiros chegou a 24,5 em 2012, isto é, quase três vezes a média da OCDE (que registrou 8,7$).{ }^{2}$ Grande parte desse contingente

* Universidade Federal do Rio de Janeiro (UFRJ), Faculdade de Educação, Programa de Pós-Graduação em Educação.

Av. Pasteur, 250 - fundos - 2o andar. Urca. Cep: 22290240. Rio de Janeiro - Rio de Janeiro - Brasil. rosana.heringer@gmail.com

** Universidade Federal do Rio de Janeiro, Faculdade de Educação da UFRJ, Departamento de Fundamentos da Educação.

Av. Pasteur, 250 (fundos) 2o andar. Urca. Cep: 22290240. Rio de Janeiro - Rio de Janeiro - Brasil. honorato@ufrj.br

Disponível em: http://portal.inep.gov.br/visualizar/-/asset_publisher/6AhJ/content/matriculasno-ensino-superior-crescem-3-8? redirect $=\mathrm{http} \% 3 \mathrm{a} \% 2 \mathrm{f} \%$ 2fportal.inep.gov.br\%2f. Acesso em: 22 set. 2014.

${ }^{2}$ Disponível em: http://portal.inep.gov.br/visualizar/-/asset_publisher/6AhJ/content/brasil-supera-media-da-ocdede-ingresso-de-estudantes. Acesso em: 22 set. 2014. é constituída dos que têm sido chamados de "novos estudantes" - com origem nas classes populares, egressos de escolas públicas e afrodescendentes. Embora a diversificação do público seja uma boa notícia, persistem problemas ainda pouco explorados.

Dados do Censo da Educação Superior de 2013, divulgados recentemente pelo Ministério da Educação, apontam um deles. Apesar da tendência de aumento no número de matrículas, pela primeira vez, em dez anos, foi registrada uma queda no número de concluintes (na rede privada de 6,7\% em relação a 2012, e, na rede pública, de 3,5\%). Esses números indicam que a permanência no curso de graduação e a conclusão dos estudos ainda é uma grande dificuldade, a despeito de ações do Estado pela democratização do acesso. A Universidade Federal do Rio de Janeiro (UFRJ), que, em 2011, passou a ocupar o primeiro lugar das instituições federais de ensino superior com relação ao número de matrículas, também parece estar sendo desafiada pela questão da permanência e conclusão dos estudos, o que é evidente nos números que apresenta.

Desde 2007, com a adesão ao Programa 
de Apoio ao Plano de Reestruturação e Expansão das Universidades Federais (REUNI), o Conselho Universitário da UFRJ elaborou 14 novas resoluções, de modo a viabilizar o aumento de matrículas, a democratização do acesso, e as ações para a permanência e assistência ao estudante (Heringer; Honorato, 2014). No Gráfico 1, é possível observar o quanto ela, de fato, se expandiu, mas também, o quanto se tornou muito mais difícil conseguir uma das "novas vagas". Em 2001, foram oferecidas 6.118 vagas para ingressantes; em 2011, 10.406 vagas. A taxa de crescimento anual foi de 6\%. Por outro lado, vemos que, em 2001, foram 59.617 candidatos inscritos; em 2011, 218.435 - uma taxa de crescimento anual de $15 \%$. A relação candidato-vaga passou de 9,7 para 21 (mais que dobrou).

Gráfico 1 - Evolução do número de vagas oferecidas e candidatos inscritos UFRJ - 2001-2011

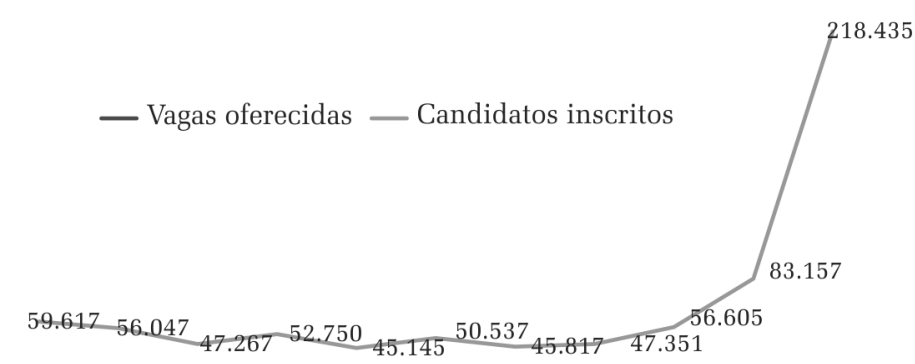

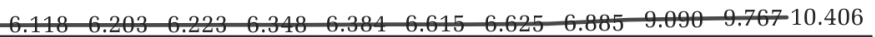

20012002200320042005200620072008200920102011

$\stackrel{0}{\rightleftharpoons} \mathrm{F}$

Fonte: Elaboração própria a partir de dados divulgados pelo MEC/Inep. Disponível em:

http://portal.inep.gov.br/superior-censosuperior-sinopse. Acesso em: 24 set. 2014.

Notas: 1) Candidatos inscritos = Vestibular e Sistema de Seleção Unificada a partir de 2011

2) Inclui dados de cursos presenciais e à distância.

No Gráfico 2, é possível observar a grande expansão no número de matrículas na UFRJ: 25.379 no início do período analisado e 39.856 no fim. A taxa de crescimento anu$\underset{*}{*}$ al (assim como a de vagas oferecidas) foi de \& 5\%. Os ingressantes passaram de 6.333 para 今 11.962 - o que equivale dizer que o crescimen-

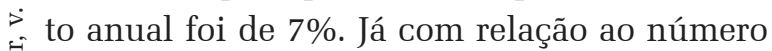
de concluintes, ele nunca passou da casa dos quatro mil. Enfim, as recentes mudanças nas formas de seleção de alunos e as ações para a permanência e assistência ainda não se fizeram impactar nessa Universidade em termos de conclusão dos estudos. A UFRJ abriu mão de vestibular próprio, adotando o Sistema de Seleção Unificada (Sisu) e a reserva de vagas (cotas para estudantes de escola pública e também a cota racial) e, entre outras ações, criou uma superintendência para tratar das políticas de permanência e assistência estudantil.

Desse modo, são importantes as iniciativas de estudos e pesquisas que visem a investigar a evasão, a permanência e também o destino de indivíduos e grupos menos privilegiados da sociedade brasileira que acessam o ensino superior. Igualmente, é fundamental analisar a efetividade de políticas públicas a fim de ampliar e diversificar a oferta de vagas nesse nível de ensino. Tomamos como ponto de partida os alunos cotistas e beneficiários do Programa de Auxílio ao Estudante do curso de Pedagogia da UFRJ com ingresso em 2011 e 2012 (as primeiras turmas com reserva de vagas para estudantes de escola pública). Até 2007, o curso de Pedagogia recebia duas turmas de ingressantes por ano (uma por semestre), no turno da tarde. Agora, são duas turmas no primeiro semestre (turno da manhã e da tarde) e uma turma no turno da noite no segundo semestre (cerca de 150 alunos anuais).

Primeiramente, a escolha de estudantes de Pedagogia se deu pelo fato de as pesquisadoras envolvidas serem - além de professoras - membros da Coordenação de Orientação e Acompanhamento Acadêmico (COAA) desse curso e dos cursos de licenciatura atendidos pela Faculdade de Educação da UFRJ. Diariamente, lidam, portanto, com alunos que apresentam dificuldades enormes para continuar estudando e concluir seus estudos. E essas dificuldades não parecem se reduzir a uma questão econômica. Alguns deles revelam grandes problemas no acompanhamento das aulas, na redação de trabalhos e nas apresentações orais de conteúdo. Outros apenas argumentam que não conse- 
Gráfico 2 - Evolução do número de ingressantes, concluintes e matrículas UFRJ - 2001-2011
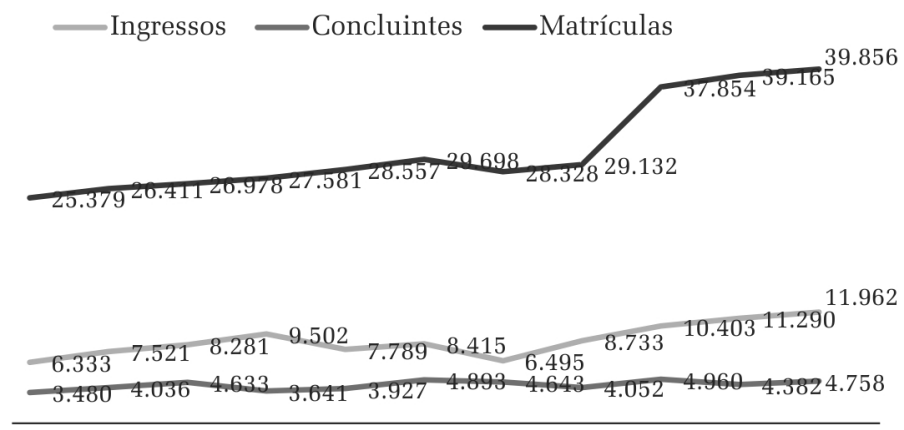

20012002200320042005200620072008200920102011

Fonte: Elaboração própria a partir de dados divulgados pelo MEC/Inep. Disponível em: http://portal.inep.gov.br/superior-censosuperior-sinopse. Acesso em: 24 set. 2014.

Notas: 1) Ingressos = ingressos por processos seletivos e outras formas (reingresso,

transferência, etc.). 2) Inclui dados de cursos presenciais e à distância. 3) A data de referência das matrículas é 30 de junho.

guem acompanhar o curso por "falta de tempo" (ou porque trabalham ou porque realizam muitas atividades de cuidado com a família restrita e extensa).

Em segundo lugar, muitos alunos desse curso relatam, durante as aulas ou em atendimento na COAA, que a Pedagogia não era sua primeira opção; chegaram lá reclassificados ou depois de muitas tentativas sem sucesso para outros cursos. O trabalho de Amaral (2011), por exemplo, confirma que, entre estudantes beneficiários do Programa Universidade para Todos, o curso de Pedagogia, em particular, e os de licenciatura, em geral, têm sido escolhidos não como um desejo, mas como um dos mais viáveis cultural e economicamente. ${ }^{3}$ A maior parte dos alunos analisados pela autora encontra-se nessa situação. Não seria ainda mais difícil permanecer no curso se ele não foi uma escolha? Não seria ainda mais penosa a permanência, considerando dificuldades econômicas e com o "trabalho acadêmico" em torno de algo que não se desejou?

Almeida (2007), ao pesquisar estudantes ditos "menos privilegiados" da Universidade de São Paulo, procurou integrar à análise do acesso ao ensino superior aquilo que chama

${ }^{3}$ Na UFRJ, de acordo com dados (de 2012) divulgados pela Superintendência Geral de Assuntos Estudantis (SuperEst), o curso só perde para Letras com relação ao apoio social das Bolsas Auxílio. Tal fato nos levou a crer que o perfil dos alunos recebidos incluía dificuldade de permanecer no curso, justificando, mais uma vez, a escolha feita. de "permanência efetiva”, uma vez que, para além da dimensão material, investiga a confrontação dos estudantes com recursos culturais, sociais e simbólicos identificados pelos pesquisados como uma demanda da vivência na universidade: local de moradia, uso do tempo, leitura de textos escritos em línguas estrangeiras, apresentação de seminários, entre outros elementos. E, dada a situação desgastante na qual estão inseridos, uma vez que ainda têm de conciliar a universidade com o trabalho, pergunta-se: "O que os leva a seguir em frente?”. Essa foi também a questão norteadora e o problema tratado em nossa pesquisa.

Trabalhos ainda mais recentes têm chamado a atenção para a "permanência efetiva", entre outros conceitos que têm sido usados pelos pesquisadores, como: "inserção plena" (Heringer; Honorato, 2014; Menezes, 2012); "permanência bem sucedida" (Gomes, 2009 apud Portes, 2006; Sousa, 2013); com "afiliação" à cultura acadêmica, institucional e comunitária (Coulon, 1998); com possibilidade de "existência com seus pares", de "coexistência" ou de "existência simbólica", de "reconhecimento pelo outro", de "legitimação", de "usufruir dos bens do mundo acadêmico" (Reis, 2013). Esses trabalhos têm mostrado que são muitos os desafios para que os estudantes concluam seus cursos, a despeito de terem conseguido acessar instituições reconhecidas como de excelência, como são, em geral, as universidades públicas brasileiras.

Estudo apresentado em 2014 (Ferreira, 2014) aponta que, de fato, o curso de Pedagogia parece ser a escolha de estudantes de famílias de baixa renda e baixa escolaridade na Universidade de Brasília (UnB). No ano de 2009, do total de alunos, 35\% das famílias tinham renda entre um e meio e três salários mínimos. Outro resultado relevante se refere à origem racial 
dos alunos. A procura pelo curso entre estudantes brancos de escolas privadas diminuiu nos últimos anos, e entre estudantes negros de escolas públicas aumentou. Entre as causas desse fenômeno estaria a redução da concorrência no "vestibular", com a oferta de bolsas de estudos nas instituições privadas e abertura de mais vagas nas públicas. Mas se, por um lado, se confirma um perfil "menos privilegiado" dos alunos que têm acesso ao curso, por outro, a perspectiva de inserção profissional não apontaria para uma tendência de ascensão social - via universidade - das famílias da "nova classe média”?

A pesquisa teve como principais objetivos identificar os fatores que limitam as chances de os estudantes ingressarem no ensino superior, lá permanecerem, e chegarem, finalmente, à conclusão dos estudos. Também foram levantados dados que dizem respeito às expectativas de inserção no mercado de trabalho e os sentidos atribuídos ao ensino superior. Com a análise, pretendemos contribuir para o aprimoramento das políticas de permanência e assistência ao estudante na UFRJ, particularmente em sua Faculdade de Educação. Acreditamos, igualmente, que os resultados permitirão análises sobre as políticas adotadas recentemente pelo Ministério da Educação a fim de 농 promover a democratização do ensino supeior no país e, com efeito, ampliar as oportunidades sociais dos grupos menos privilegiados.

Neste artigo, descrevemos a metodologia utilizada na pesquisa, combinando análise documental, survey e entrevistas. Com base nessa descrição, apontamos e refletimos sobre $\underset{*}{*}$ as principais dificuldades metodológi-

$\therefore$ cas encontradas em sua realização. Essas

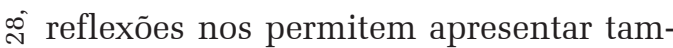

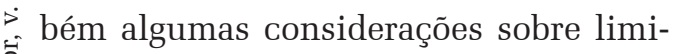
tes e desafios potencialmente colocados em outras situações de pesquisa que venham a ser desenvolvidas sobre acesso e permanência no ensino superior.

\section{ELABORAÇÃO E APLICAÇÃO DO QUESTIONÁRIO}

Uma primeira dificuldade encontrada relaciona-se à construção do questionário. Buscando desenhar um quadro detalhado do perfil dos estudantes de Pedagogia, foram elaboradas 59 questões, abordando tanto o histórico dos alunos antes de ingressarem na UFRJ, sua experiência como universitários, além de perspectivas profissionais futuras.

Tal fato resultou num questionário longo, que demandou um tempo razoável de concentração por parte dos estudantes para seu preenchimento (cerca de uma hora). Durante a aplicação do pré-teste, verificamos que algumas questões não eram autoexplicativas e demandaram reformulação para que pudessem ser compreendidas pelos alunos (por exemplo, as que pediam ordenamento das alternativas de resposta apresentadas por importância).

A aplicação dos questionários foi feita em horários de aula cedidos por professores. Após a aplicação do pré-teste, a equipe foi surpreendida pelo início da greve dos docentes das universidades federais em 2012, o que provocou o adiamento da aplicação dos questionários por vários meses.

Como retorno das aulas, a pesquisa começou a ser aplicada em novembro de 2012 e foi interrompida como recesso de final de ano. Ao se retomar a aplicação dos questionários em meados de janeiro de 2013, constatou-se que uma quantidade expressiva de alunos ingressantes não havia retornado, tendo trancado ou abandonado o curso. A Tabela 1 aponta Tabela 1 - Situação da matrícula (jun/2013)

\begin{tabular}{|c|c|c|c|c|}
\hline Períodos & Ativa & Rematrícula & Trancada & Cancelada \\
\hline 2011-1 & $56(50 \%)$ & $7(6 \%)$ & $10(9 \%)$ & $38(34 \%)$ \\
\hline 2011-2 & $31(56 \%)$ & $5(9 \%)$ & $3(5 \%)$ & $16(29 \%)$ \\
\hline 2012-1 & $62(57 \%)$ & $2(2 \%)$ & $7(6 \%)$ & 37 (34\%) \\
\hline 2012-2 & $55(95 \%)$ & 0 & $1(2 \%)$ & $2 \quad(3 \%)$ \\
\hline Total & 204 (61\%) & $14(4 \%)$ & $21(6 \%)$ & $93(28 \%)$ \\
\hline
\end{tabular}


a situação das matrículas ativas no primeiro semestre de 2013.

Tal evasão reduziu, então, o nosso universo de alunos com matrícula ativa em 2013, levando a um total de 218 alunos. Desses, foi possível pesquisar 100 estudantes (46\%), representantes de todos os períodos e turnos.

\section{BANCO DE DADOS E CODIFICAÇÃO}

O tamanho do questionário e a variedade de opções de resposta em grande parte das questões nos levaram a uma dificuldade relacionada à montagem do banco de dados e do dicionário de variáveis, nos quais gastamos mais tempo do que inicialmente previsto. Foram criadas 173 variáveis, e a digitação no SPSS foi feita por duas estudantes bolsistas de iniciação científica e duas voluntárias.

Além da digitação das respostas às questões fechadas, codificamos e digitamos também as respostas a quatro questões abertas, relacionadas principalmente com as considerações dos alunos sobre o acesso à universidade e com as perspectivas futuras de inserção profissional. Em relação a esse último aspecto, observamos que as características que os alunos consideram relevantes para o mercado de trabalho, em geral, se referem menos a aspectos da divisão social e técnica e mais a aspectos atitudinais, como, por exemplo, "dinamismo", "humildade" ou "iniciativa".

\section{ENTREVISTAS}

Ao final do questionário, solicitamos que os alunos indicassem se tinham disponibilidade para uma eventual entrevista. Dos 100 respondentes, 42 se disponibilizaram para entrevistas, informando nome e contato. Desses, foram pré-selecionados 30 estudantes para serem entrevistados, buscando-se reunir, nesse grupo, alunos com diferentes características em termos de condição de ingresso (cotista ou não cotista), autodeclaração de cor, gênero, bairro de residência, o fato de receber ou não bolsa do Programa de Auxílio ao Estudante (como, por exemplo, a Bolsa Auxílio) e participar ou não em algum outro programa com bolsa acadêmica (por exemplo, Programa de Iniciação Científica, Programa de Iniciação à Docência, etc.).

Os resultados do survey apontaram a presença de $23 \%$ de alunos cotistas, proporção coerente com os números disponibilizados pela coordenação do curso para o conjunto dos ingressantes de 2011 e 2012.

Quando passamos a levantar o perfil e a contatar os estudantes a serem selecionados para entrevista, observamos que alguns deles omitiram, no questionário, a informação de que eram cotistas ou recebiam Bolsa Auxílio, talvez preocupados em ser identificados e receber alguma sanção por algo que responderam.

A fim de nos certificar sobre a situação de ingresso e recebimento ou não de Bolsa Auxílio, obtivemos uma listagem fornecida pela Pró-Reitoria de Graduação (PR-1), que permitiu a checagem dessas informações, chegando, então, à verificação dos cotistas e bolsistas. Com base na combinação desses dados, foi possível selecionar os entrevistados com melhor critério.

Foram realizadas onze entrevistas com alunos de diferentes perfis. Para as entrevistas, foi elaborado um roteiro que continha uma parte comum, introdutória, e, em seguida, questões específicas para cada tipo de estudante.

As entrevistas duraram cerca de uma hora e trouxeram informações muito ricas e detalhadas sobre as diferentes trajetórias. Entretanto, observamos que o roteiro permitiria explorar muitos outros detalhes em entrevistas com maior duração, caso houvesse disponibilidade.

Também cabe registrar que houve dificuldade no agendamento das entrevistas, pois alguns alunos, ao serem contatados, não se disponibilizaram, e outros, apesar de terem confirmado, não compareceram na data marcada. 


\section{BASES DE DADOS DA UFRJ}

Também houve dificuldades em relação à disponibilidade e acesso aos dados da UFRJ referentes ao acesso e permanência dos estudantes. Uma primeira questão refere-se ao fato de que, com a adesão ao Sisu (Sistema de Seleção Unificada), a UFRJ não possui mais uma base própria de dados socioeconômicos sobre os seus candidatos e ingressantes, pois tal base, agora, refere-se ao conjunto de estudantes selecionados pela nota do Exame Nacional do Ensino Médio (ENEM). Por essa razão, não foi possível acessar diretamente os dados sobre os ingressantes no curso de Pedagogia em 2011 e 2012.

De acordo com a Resolução No. 02/2011 do Consuni (Conselho Universitário) da UFRJ (UFRJ, 2011), está autorizado o imediato acesso por possíveis interessados aos microdados do sistema de seleção para acesso, bem como aos indicadores de desempenho estudantil. Entretanto, de acordo com a então Pró-Reitora de Graduação, apesar dessa Resolução, os dados sobre desempenho são armazenados num tipo de software que só o Núcleo de Computação Eletrônica (NCE) da Universidade pode manipular. Por essa razão, dependemos da boa vontade da PR-1 em enviar a lista dos ingres-

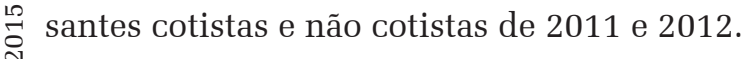

: Outra questão surgida em relação aos dados sobre ingresso diz respeito ao conjunto de informações sobre a UFRJ levantadas através do Censo da Educação Superior. Embora os microdados do Censo estejam disponíveis para consulta, são muitos os casos missing (sem inホ formação ou não preenchidos), dificultando a \& sua análise. Essa situação prejudica, por exem今 plo, a análise das informações sobre os estudantes da UFRJ segundo sua autoclassificação de cor, um dos quesitos em que o número missing é mais elevado. Nesse sentido, é importante destacar que, embora seja fundamental a informação consolidada em nível nacional, é imprescindível que cada instituição de ensino superior seja responsável pela coleta da forma mais completa possível das informações referentes a seu corpo discente.

\section{CONSIDERAÇÕES FINAIS}

O quadro brevemente descrito aqui aponta para alguns aprendizados e desafios que se apresentam para aqueles que se lançam à tarefa de pesquisar o perfil de estudantes universitários, principalmente em relação a seu ingresso e inserção na vida universitária. Observamos que ainda é preciso aperfeiçoar os sistemas de coleta de informações, melhorar os instrumentos de pesquisa e também ter mais disponibilidade de informações institucionais consolidadas que permitam avançar na composição de um quadro mais completo desses "novos estudantes" universitários que passam a frequentar as instituições públicas de ensino superior.

Esses estudos se fazem cada vez mais necessários no momento em que as matrículas na educação superior pública se expandem de forma consistente, tanto através de novos cursos e novos campi, como também por meio de novas instituições que, em sua estruturação, podem, eventualmente, aprender a partir da experiência das mais antigas e consolidadas, estabelecendo novas práticas institucionais.

Também é muito importante avançar no monitoramento das trajetórias de estudantes beneficiados pelas cotas sociais e raciais e também das políticas de permanência, a fim de avaliar, em médio prazo, quais são as mais eficazes para promover o melhor desempenho e o sucesso na vida acadêmica desses estudantes.

Recebido para publicação em 15 de janeiro de 2015 Aceito em 15 de março de 2015

\section{REFERÊNCIAS \\ ALMEIDA, Wilson Mesquita de. Estudantes com desvantagens econômicas e educacionais e fruição da universidade. Caderno CRH, Salvador, v. 20, n. 49, p. 35-46, Jan./Abr. 2007.}


AMARAL, Daniela Patti do. O ProUni e a conclusão do ensino superior: questões introdutórias sobre os egressos do programa na zona oeste do Rio de Janeiro. Relatório de Pesquisa (Pós-Doutorado em Administração Pública). Rio de Janeiro: FGV, 2011.

BOURDIEU, Pierre. A escola conservadora: as desigualdades frente à escola e à cultura. In: NOGUEIRA, Maria Alice; CATANI, Afrânio (Orgs.). Escritos de Educação. 11 ed. Petrópolis: Vozes, 2010 [1966].

Futuro de classe e causalidade do provável. In: NOGUEIRA, Maria Alice; CATANI, Afrânio. (Orgs.). Escritos de Educação. 11 ed. Petrópolis: Vozes, 2010 [1974].

CARDOSO, Liana da Silva. Formular e desenhar uma pesquisa: exercícios e notas. Rio de Janeiro: Papel \& Virtual, 2000

COULON, Alain. Condição de estudante: a entrada na vida universitária. Salvador: EDUFBA, 1998.

CUSTÓDIO, Jorge. Querendo modificar "destinos" sociais: experiências e projetos de trabalhadores cariocas e a formação universitária. Dissertação (Mestrado em Sociologia). Rio de Janeiro: UFRJ, 2001.

DUBET, François. Sociologia da experiência. Lisboa: Instituto Piaget, 1994.

FERREIRA, Marcos Felipe Ferreira. O curso de Pedagogia: perfil de ingresso, inserção profissional e promoção social. Programa de Pós-Graduação em Educação, Universidade de Brasília. Brasília: UnB, 2014.

GOMES, Alfredo Macedo; MORAES, Karine Nunes. Educação superior no Brasil contemporâneo: transição para um sistema de massa. Educ. Soc., Campinas, v. 33, n. 118, p. 171-190, jan./mar. 2012.

HERINGER Rosana; FERREIRA, Renato. Análise das principais políticas de inclusão de estudantes negros no ensino superior no Brasil no período 2001-2008. In: Paula, Marilene de; HERINGER, Rosana. Caminhos Convergentes: estado e sociedade na superação das desigualdades raciais no Brasil. Rio de Janeiro: Fundação Heinrich Boll/ ActionAid, 2009

O Próximo passo: as políticas de permanência na universidade pública. In: PAIVA, A. R. (org.). Ação afirmativa em questão: Brasil, Estados Unidos, Africa do Sul e França. Rio de Janeiro: Ed. Pallas, p. 74-99, 2013.

; HONORATO, Gabriela. Políticas de Permanência e assistência no ensino superior público: o caso da Universidade Federal do Rio de Janeiro (UFRJ). In: BARBOSA, M. Ligia (org.). Ensino superior: expansão e democratização. Rio de Janeiro: 7Letras, p. 315-350, 2014

HONORATO, G. S. Estratégias coletivas em torno da formação universitária: status, igualdade e mobilidade entre desfavorecidos. Dissertação (Mestrado em Sociologia). Rio de Janeiro: UFRJ, 2005.
MENEZES, S. C. de. Assistência estudantil na educação superior pública: o programa de bolsas implementado pela Universidade Federal do Rio de Janeiro. Dissertação (Mestrado em Serviço Social). Rio de Janeiro: PUC-Rio, 2012.

MOEHLECKE, Sabrina. Ação afirmativa no ensino superior: entre a excelência e a justiça social. Educação e Sociedade, Campinas, v. 25, p.757-776, Especial, out. 2004.

NOGUEIRA, Maria Alice. Trajetórias escolares, estratégias culturais e classes sociais. Notas em vista da construção do objeto de pesquisa. Teoria \& Educação, Porto Alegre, n. 3, 1991.

OLIVEIRA, João Ferreira de; Dourado, Luiz Fernandes; Amaral, Nelson Cardoso, 2006. Desafios e perspectivas de uma política para as Instituicões Federais de Ensino Superior (IFES). In: Moehlecke, Sabrina; Catani, Afrânio Mendes et. al., Políticas de acesso e expansão da educação superior: concepções e desafios. Brasília: MEC/ INEP, 2006.

PEREIRA, Adriana da Silva Alves. Sucesso escolar de alunos dos meios populares: mobilização pessoal e estratégias familiares. Dissertação (Mestrado em Educação). Belo Horizonte: PUC-Minas, 2005.

PORTES, Écio Antônio. Algumas dimensões culturais da trajetória de estudantes pobres no ensino superior público: o caso da UFMG. Revista Brasileira de Estudos Pedagógicos, Brasília, v. 87, n. 216, p. 220-235, maio/ago. 2006

REIS, D. B. Continuar ou desistir? Reflexões sobre as condições de permanência de estudantes negros na UFRB. In: SANTOS, G. G. dos; SAMPAIO, S. M. R. (Orgs.). Observatório da vida estudantil. Universidade, responsabilidade social e juventude. Salvador: EDUFBA, 2013

SOUSA, Leticia Pereira, 2013. Reserva de vagas na Universidade Federal de São João Del-Rei: o perfil dos beneficiados pela Ação Afirmativa 2 em 2010. Dissertação de Mestrado apresentada ao Programa de Pós-Graduação: Processos Socioeducativos e Práticas Escolares, Universidade Federal de São João del-Rei. 2013.

SOUSA, L. P.; PORTES, E. A. As propostas de políticas/ acões afirmativas das universidades públicas e as políticas ações de permanência nos ordenamentos legais. Revista Brasileira de Estudos Pedagógicos, Brasília, v. 92, n. 232, p. 516-541, set./dez. 2011.

UFRI. Resolução CONSUNI No. 02/2011 - Autoriza o imediato acesso aos microdados do seu sistema de ingresso "vestibular", bem como aos indicadores de desempenho estudantil. BUFRJ, n. 8, 24 fev. 2011. 


\section{ELEMENTS FOR AN ANALYSIS OF QUOTA STUDENTS AND SCHOLARS IN THE COURSE OF UFRJ EDUCATION}

\author{
Rosana Heringer \\ Gabriela de Souza Honorato
}

The article deals with the great expansion in opportunities for access to higher education in Brazil, with special emphasis on the case of one of its major institutions - the Federal University of Rio de Janeiro. We point and reflect on the first methodological difficulties encountered in the construction of data collection instruments as are the survey and semi-structured interviews. These were used to take as object of study the students of Pedagogy entering in 2011 and 2012 (first groups after the institution of quotas for public school students), that had a profile of economic and cultural difficulties for completion of studies. The reflections gathered synthesize some of the potential limits and challenges in studies that aim to contribute to the planning, design and improving of institutional policies for democratization of access, permanence and assistance to the so-called 'new students'.

KEY wORDS: Methodology. Higher education. Affirmative action

\section{ÉLEMENTS POUR UNE ANALYSE DES ETUDIANTS ADMIS PAR QUOTAS AU COURS DE PÉDAGOGIEÀ L'UFRJ}

\author{
Rosana Heringer \\ Gabriela de Souza Honorato
}

Larticle traite de la grande expansion dans les possibilités d'accès à l'enseignement supérieur au Brésil, avec un accent particulier sur le cas d'une de ses grandes institutions - l'Université Fédérale de Rio de Janeiro. Nous essayons de réfléchir sur les difficultés méthodologiques rencontrées dans la construction d'instruments de collecte de données soit l'enquête quantitative ou les entretiens semistructurés. Ils ont été utilisés pour prendre comme objet d'étude les élèves du cours de Pédagogie admis en 2011 et 2012 (premiers groupes à avoir une politiques de discrimination positive pour les élèves des écoles publiques), qui ont un profil des difficultés économiques et culturelles pour la finalisation des études. Les réflexions recueillies synthétisent certaines des limites et des défis potentiellement posés dans les études qui visent à contribuer à la planification, la conception et la mise en œuvre des politiques institutionnelles de démocratisation de l'accès, de la permanence et de l'assistance aux soi-disant "nouveaux étudiants".

Mots-Clés: Méthodologie. Enseignement supérieur. La discrimination positive.

Rosana Heringer - Doutora em Sociologia. Professora e pesquisadora da Universidade Federal do Rio de Janeiro (UFRJ), Faculdade de Educação, Programa de Pós-Graduação em Educação e dos cursos de graduação. Integra o Laboratório de Pesquisas em Oportunidades Educacionais, o Grupo de Pesquisa em Sistemas Educacionais e o Laboratório de Pesquisa em Ensino Superior, todos na UFRJ. Publicações recentes: Políticas de permanência e assistência no ensino superior público e o caso da Universidade Federal do Rio de Janeiro (UFRJ), In: Ensino superior: expansão e democratização, Ed. 7Letras, 2014, coautoria ; Expectativas de acesso ao ensino superior: um estudo de caso na Cidade de Deus, Rio de Janeiro (2013, e-book); Diversidade, relações raciais e étnicas e de gênero no Brasil contemporâneo, in: O Progresso das Mulheres no Brasil (2003-2010) - (coautoria), 2011.

Gabriela de Souza Honorato - Doutora em Sociologia. Professora da Universidade Federal do Rio de Janeiro, Faculdade de Educação da UFRJ, Departamento de Fundamentos da Educação. Pesquisadora do Laboratório de Pesquisas em Oportunidades Educacionais e do Laboratório de Pesquisa em Ensino Superior da mesma Universidade. Áreas de atuação: Produção e Efeitos das Desigualdades Sociais; Desigualdades e Distribuição de Oportunidades Educacionais; Educação Superior e Inclusão Social; Educação e Trabalho; Sociologia da Educação; Ensino de Sociologia; Análise de Impactos Socioeconômicos de Grandes Projetos de Investimento. Publicações recentes: Políticas de permanência e assistência no ensino superior público e o caso da Universidade Federal do Rio de Janeiro (UFRJ). In: Ensino superior: expansão e democratização, 7Letras, 2014, coautoria; A permanência de estudantes de origem popular no ensino superior: o caso dos alunos beneficiários do ProUni. Revista de Humanidades, Tecnologia e Cultura, Faculdade de Tecnologia de Bauru, 2011. 